\title{
Design and Analysis a Low-Cost Cementitious Waterproofing Mixture Based on the Solution of a Mathematical Model
}

\author{
Fatima Alsaleh $^{1}$, Feras Al Adday ${ }^{2 *}$, Mohamed Bassam Hamami ${ }^{3}$ \\ ${ }^{1,3}$ Department of Transportation Engineering, Faculty of Civil Engineering, University of Aleppo. \\ ${ }^{2}$ Middle East University, Amman, Jordan \\ ${ }^{3}$ Mathematics Department, Faculty of Science, University of Aleppo
}

Received: 16/09/2020

Accepted: 13/11/2020

Published: 20/03/2021

\begin{abstract}
Most of the investigation results of engineering studies depend on the principle of trial and error in decision-making, which requires a lot of time and effort and does not guarantee to reach the optimum solution. Whereas, mathematical models provide mathematically proven optimum solutions to problems. This research aims to exploit the huge quantities of fine recycled aggregates (FRA) from the destroyed buildings and infrastructure of the city of Aleppo to design a cement-based waterproofing concrete mixes, by developing a mathematical model. The optimum proportions of the materials included in the composition of cement-based waterproofing concrete mixes have been founded by this model which is derived and solved by a simulated annealing method. Experimental results showed the efficiency and accuracy of the proposed model in determining the optimal quantities of the mixture content with a minimum cost according to the required engineering conditions.
\end{abstract}

Keywords: Fine Recycled Aggregates, Cement-Based Waterproofing Mixture, Linear and Nonlinear Constrains, Simulated Annealing Method

\section{Introduction}

Concrete buildings are usually exposed to different environmental and climatic conditions that may negatively affect their efficiency. Moisture resulting from the exposure of buildings to water is one of the most important problems that affect not only structural damage but also affect the health of the residents of these buildings [1]. The moisture leaking into the building causes damage to the internal and external cladding elements, it also has another destructive role on reinforced concrete elements upon constant exposure to moisture, as it leads to the migration of salts from the concrete, affecting the properties of the concrete. Not limited to this only, but may extend to the reinforcement steel and lead to rust and weaken its sections [2]. Therefore, waterproofing is the first step to solving this problem to preserve the structural elements and increase the service life of the facility. Waterproofing can be defined as the process by which surfaces of building elements and joints are treated to prevent water from leaking into or through them in the event of hydrostatic pressure [3]. While waterproof materials are generally known as materials that are often in the form of one or more layers or membranes that are implemented on surfaces or ceilings to prevent water from seeping into the structural elements with or without hydrostatic pressure, as for moisture insulation materials they are materials in the form of layers or strips placed within walls to reduce water leakage without hydrostatic pressure, and to be executed directly above the natural ground level or above the ceiling level [4]. The waterproofing is divided according to the method of its implementation into two main types, namely positive insulation, in which the source of moisture is isolated so that it prevents its access to the structural element, thus preserving its properties. As for negative insulation, which is done if the leaked water has entered the element to reduce moisture damage to the cladding and inner medium of the structural element, this type is not resorted to except in very special cases [5]. The waterproofing materials are divided into two main parts: the films are either bituminous or polyvinyl chloride (PVC) films or polyethylene (PE) films of different types of HDPE, LDPE, LLDPE, and VLDPE. These materials vary greatly according to their chemical composition, these are divided into waterproofing materials with a water-based, polymeric-based, bituminous-based, cement-basis, and other. These materials are called liquid waterproofing coatings. Or in the form of a mixture of two components, one in the form of a cement-base and the other in the form of a polymeric-basis [6,7]. Cement-based waterproofing mixes are the most common type due to their ease of use and relatively cheapness as well as its homogeneity with the concrete elements covered by $[8,9]$. Liquid waterproofing coatings it can be formed from only one compound, which is a solid (powder) mixed with water to produce a coating, or two compounds, one of them is solid and the other is a liquid, which produces the waterproofing

Corresponding author: Feras Al Adday, Faculty of Engineering, Middle East University, Amman, Jordan, falkhalil@ meu.edu.jo 
coatings if mixed, it can be polymeric, when mixed with the solid compound, it forms a high elasticity, weatherproof, and adhesion film. The solid compound in cement coatings usually consists of a mixture of cement with fillers powder or natural sand $[10,11]$. The waterproofing materials constitute the basic element in designing insulating concrete mixes [12]. Many factors play a big role in the process of designing insulating cement mixes, such as strength, permeability, and durability in addition to economic feasibility, especially in places that are constantly exposed to moisture and water submersion that require continuous treatment $[13,14,15]$. The basis of the process of designing concrete mixtures is the accurate determination of the proportions of the materials involved in it, it is possible to change the specifications of the physical and chemical mixture by changing the quality and proportions of the formed materials, especially if the concrete mixture contains the FRA, due to the difference in the specifications of those materials from the natural aggregate, such as the water absorption [16]. The war in Syria has produced, in recent years, tremendous damage to buildings and infrastructure, which has resulted in very large quantities of solid waste, which can be used in many engineering applications $[17,18]$. Which made the disposal and recycling of these solid waste an urgent economic and environmental necessity. By using them in various applications to ensure the utilization of the occupied spaces and the non-depletion of natural resources in the reconstruction phase. Various studies have proven that the coarse recycled aggregate can be used in various civil engineering projects, such as asphalt and concrete mixtures and others [19-22], while the use of FRA was limited to some applications.

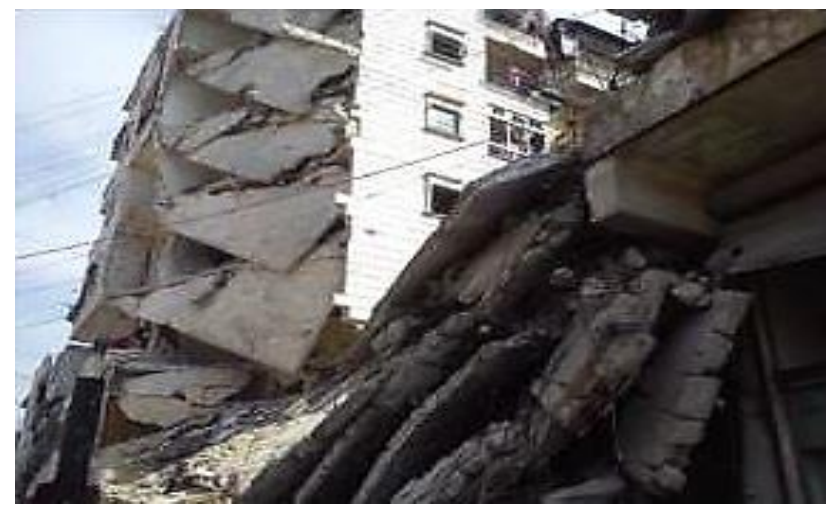

Figure 1: Destruction and rubble in the war-affected areas of the city of Aleppo [17]

With regard to previous studies, mathematical and statistical modeling has been used in the design concrete mixtures by many researchers. Vengadeshwari and Reddy, 2013 [23] applied heuristic algorithms to design concrete mixtures to obtain the optimal solution away from the experimental principle adopted in traditional engineering studies, where the best design has been developed that determines the proportions of materials used in concrete mixtures to obtain the mixture with the lowest cost and weight in addition to reliability. The other uses of artificial intelligence was made by Kale, Kute, 2014 [24] to design concrete mixtures based on modeling using artificial neural networks to avoid the implementation of a large number of experimental mixtures to choose the best combination of materials involved in the design of the concrete mixture and to achieve the required specifications according to the Indian code. Also, Gupta, 2013 $[25,26]$ used artificial neural networks trained in the technique of backward error propagation to predict the compressive strength values of 55 concrete mixtures with different ratios of cement, coarse gravel, sand, water and the fineness modulus at 7,14, and 28 days of curing. Nano-Silica was also added to other concrete samples according to the same previous method for predicting compressive strength. Another study on pre-cast concrete mixes was carried out by Bilgil, A, 2012 [27] using artificial neural networks to determine the behavioral properties of concrete, which included Slump value, yield stress, and viscosity data for a number of concrete mixtures used.

Modified and developed forms of the mathematical models presented by Papadakis, 2000 [28]. Mathematical models have been modified to determine the values of the ratios of addition of some substances such as: Silica-fume and Fly ash with low and high calcium so that the modified model describes the spread of carbonation and penetration of chlorides to concrete. The development of mathematical modeling methods for the formation of mixtures concrete have been achieved to include Multiple target mathematical relationship, where the Toklu, 2005 [29] developed a multi-objective mathematical model to determine the mixing ratios of aggregate in concrete mixtures at the lowest cost. The proposed model was solved using heuristic algorithms after the analytical mathematical methods failed to reach an optimal solution. As for the insulating cement-based mixes, whether it is paint or mortar, there is a lack of research that tried to find mathematical models to reach the best ratios of materials included in the composition of the concrete mixture, including: What Zhang and Zheng, 2012 have done [30], where they prepared and insulating capillary crystal mixes with a cement-basis, the basic structure of which is made of Portland cement and fine aggregates, while Portland cement was used with a substance composed of quartz powder in addition to five other materials as a coating for the mixture, and then they applied software to analyze the test data to obtain an optimal relationship that gives the proportions of the input materials In the composition of the concrete mixture. Each of the research groups, Zhang, et.al [31] contributed to developing insulating capillary crystal mixes with a cement basis and determining the quantities of active substances by means of orthogonal tests. The proportions of cement to sand were also determined with the active materials to obtain the composition of the insulating material according to the optimal proportions. The results showed that all the properties of the developed insulation material meet the standard specifications of bonding stress and leakage resistance. A new addition in Bohus, et.al's search [32] is the use of cement with the Fly ash according to experimentally determined percentage. Similarly, work has been done by Pushkarova, K., et.al, 2015 [33] to find a crystal mixture to protect concrete structures and increase their resistance to water and freezing. Optimum of the proportions of materials included in the mixture were also experimentally done.

As for the insulating cement mix with an elastic polymericbasis studied by Lecha and Joanna Juliab, 2011 [34], Where Optimum of this mixture were carried out using relationships that connection the composition to the engineering specifications of the mixture (flexibility, insulation and water vapor permeability). Optimum of a mathematical model were done to obtain the 
optimal proportions of the mixture through statistical experiments by evaluating the different combinations of mixtures. The resulting mixtures were tested depending on the desired output of the generated statistical function. The results obtained showed the efficiency of the statistical model in designing the insulating covering mixtures of cement basis.

Based on the previous studies that have been presented, it is evident that the cement-based waterproof concrete mixes were not designed according to a specific mathematical model solution that fulfills the required engineering conditions at the lowest possible economic cost. In this paper, an innovative mathematical model has been proposed to determine the optimal proportions of the materials included in composition of waterproof concrete mixes. In addition to making use of the FRA resulting from the waste of destroyed buildings and infrastructure in the city of Aleppo, A mathematical model is derived and solved by simulated annealing method.

\section{Materials, tools and research methods 2.1 Research materials}

The following materials were used in the research according to the appropriate standard specifications:

- Cement: Cement type -32.5 was used and it was ensured that it meets the Syrian standard specifications 1673/1996 and 75/1998.

- Water: Drinking water has been used that meets the Syrian standard 2007/45.

- Sand and fillers: In this research, FRA were used, resulting from destroyed buildings in the neighborhoods of the Salah alDin area, passing through the sieve opening $0.425 \mathrm{~mm}$, which includes fine sand whose dimensions range between $0.425 \mathrm{~mm}$ and $0.075 \mu$, in addition to the powder whose diameter is less than $75 \mu$ according to the ASTM E11-16. The specific gravity and water absorption percentage of the three samples of FRA were measured at average of 2.6 and $6.98 \%$, respectively. It was observed that the absorption of FRA of water is higher than similar samples from NA, which is consistent with the reference studies.

- It was also confirmed that the samples are free of impurities (clay and exotic materials soluble). As for the sand equivalent, the average value for the three samples was $69.3 \%$ (the acceptable value for the concrete is $75 \%$, which increases with the increase in the strength, as it is $80 \%$ for the highly strength concrete), since the required strength of waterproofing mixes are less than concrete in general, and it decreases whenever the surfaces are not loaded, the sand equivalent value of the FRA used in the mixture is considered acceptable.

- Bond: Acrylic dissolved in water of 1.05 specific weight was used.

\subsection{Mathematical model for designing dielectric mixtures}

The mathematical design model is based on the mathematical relationships governing the material that give the basic properties to be achieved. These relationships are classified into two groups. The first is the relationship that represents the properties or values necessary for the design to achieve its objective, and the second is the relationships that can be considered constraints imposed by the practical and implementation conditions.

\subsubsection{Limitations of the Mathematical Model}

a. Permeability condition: Water isolation can be achieved in more than one method, but all methods can be summarized by reducing the permeability of the material by reducing the percentage of material voids to a minimum or closing the voids so that a specific substance enters the pores and closes them mechanically or chemically as in the case of crystal cement materials [30]. In this research, work has been done to achieve a minimum permeability by reducing the percentage of voids in the samples in order to achieve a maximum water-proof ratio. The sum of the absolute unit volumes of the materials forming the cement-base waterproof mixture is equal to one that are designed with taking into account the homogeneity of the units as shown in equation (1).

$\mathrm{V}=\mathrm{V}_{\mathrm{c}}+\mathrm{V}_{\mathrm{p}}+\mathrm{V}_{\mathrm{w}}+\mathrm{V}_{\mathrm{f}}+\mathrm{V}_{\mathrm{v}}=1$

where: $V_{v}, V_{c}, V_{p}, V_{w}, V_{f}$ are the volume of cement, polymeric bond, water, and sand and filler, and voids respectively. Thus, the volume of voids in this mixture can be obtained as follows:

$\mathrm{V}_{\mathrm{v}}=1-\mathrm{V}_{\mathrm{c}}+\mathrm{V}_{\mathrm{p}}+\mathrm{V}_{\mathrm{w}}+\mathrm{V}_{\mathrm{f}}$

By substituting the weights instead of volumes, with making some reforms to the equation (2) and adopting the proportion of voids instead of their volume, equation (2) becomes as follows:

$$
A \%=\frac{V v}{V}=\frac{1-\frac{\gamma_{w}}{g}\left(\frac{W_{c}}{G_{c}}+\frac{W_{p}}{G_{p}}+\frac{W_{w}}{G_{w}}+\frac{W_{f}}{G_{f}}\right)}{V}
$$

where: Wc , Wp , Ww , Wf are the weights of cement, polymeric bond, water, and sand and filler, respectively; $\gamma_{w}$ is unite weight of water; Gc , Gp, Gw , Gf are the specific gravity of cement, polymeric bond, water, and sand and filler, respectively. By making this ratio minimum, and considering that the unit volumes equal to $1, \mathrm{n}$ is the number of components in the mixture design, the general form of equation (3) becomes as follows:

$$
A \%=1-\frac{\gamma_{w}}{g} \sum_{i=1}^{n} \frac{W_{i}}{G_{i}} \rightarrow M i
$$

In general, the voids percentage of concrete mixtures according to the American method (ASTM) of design ranges between 0.5 $3 \%$, depending on the maximum size of the aggregates and the workability [35]. These numbers are very large in the case a waterproofing material. Therefore, the value of the voids percentage was adopted at the minimum value $A=10-22$ in the final model, which is the lowest value that gives a solution to the mathematical model within the solution space.

b. Ratio of sand and filler (FRA) to cement: Several initial experiments were conducted, starting with the proportions of sand to cement (Wf / Wc ) approved for regular mortar according to the ASTM C778-74 and the ISO system, which are 2.75 / 1 and $3 / 1$, and then these ratio reduced according to the results of the 
preliminary study of the cement insulation materials to suit the available materials, in order to achieve a good consistency that ensures ease of implementation. It has been adopted field of change Wf / Wc $\in$ [0.5-2.5].

c. The ratio of water to cement: The ratio of water to cement (Ww / Wc) in different concrete mixes greatly and effectively affects the compressive strength of concrete mixtures, as the compressive strength increases with increasing this ratio until reaches a maximum value that matches the best ratio and then returns to decrease [34][35][36]. An analytical study was conducted for research and studies interested in cement insulation materials, taking into account the specifications of the different materials included in the designs, in addition to monitoring the increase in the water percentage at a rate of more than $7.5 \%$, since FRA used have a high absorption rate, and thus the field $\mathrm{Ww} / \mathrm{Wc}$ $\epsilon$ [0.3-1.2] was adopted as a limitation for the studied model.

d. Ratio of acrylic material to cement: a preliminary analytical study completed for different polymeric cement insulating materials. After performing a number of preliminary experiments with different mixing ratios, the change field was determined within the range $\mathrm{Wp} / \mathrm{Wc} \epsilon$ [0.25-0.7].

e. The relationship of the correlation of the percentages of cement and filler with water was studied so that the permeability condition is achieved physically, and the restriction was derived mathematically to achieve the condition within the required field [37].

f. All variables in the mathematical model fulfill the nonnegativity condition.

\subsubsection{The target function}

The target function in the mathematical model was adopted as an economic cost function (a minimal cost function), which is a linear programming that represents the price of the mixture in Syrian pounds according to the price of each component offered in the local market until the date of preparing the study, price and specific gravity can be shown in the table1. Thus the target function in the general formula is given as:

$$
P_{\text {Total }}=\sum_{j=1}^{n} P_{j} W_{j} \rightarrow \text { Min }
$$

whereas, $\mathrm{Pj}$ is the price of the component and its weight is $\mathrm{Wj}, \mathrm{n}$ is the number of elements of the mixture. Therefore, the target function must strive to its minimum value in order to achieve the economic benefit required in the case of using of FRA.

Table1: The specific gravity and price in Syrian pounds for each component of the mixture

\begin{tabular}{lllll}
\hline Component & Cement & $\begin{array}{l}\text { Fine } \\
\text { Recycled } \\
\text { Aggregate }\end{array}$ & Acrylic & Water \\
\hline $\begin{array}{l}\text { Specific } \\
\text { gravity }\end{array}$ & 3.15 & 2.6 & 1.05 & 1 \\
Price: SP/gr & 0.055 & 0.01 & 1.5 & 0.001 \\
\hline
\end{tabular}

$$
\left[\begin{array}{l}
\operatorname{Min} f(w)=0.055 W_{c}+1.5 W_{p}+0.001 W_{w}+0.01 W_{f} \\
1-\frac{1}{0.981}\left(\frac{W_{c}}{3.15}+\frac{W_{p}}{1.05}+\frac{W_{w}}{1}+\frac{W_{f}}{2.6}\right) \leq 1 \times 10^{-22} \\
0.5 \leq\left(\frac{W_{f}}{W_{c}}\right) \leq 2.5 \\
0.3 \leq\left(\frac{W_{w}}{W_{c}}\right) \leq 1.2 \\
0.25 \leq\left(\frac{W_{p}}{W_{c}}\right) \leq 0.7 \\
0.4 W_{c}+0.03 W_{f} \leq 0.5 W_{c}+012 W_{f} \\
W_{c}, W_{f}, W_{p}, W_{w} \geq 0
\end{array}\right] \text { Eq (6) }
$$

Thus, it can represent the final form of the mathematical model for the required design as it is in the general equation (6). Heuristic algorithms, such as the Optimization Particle Swarm have been applied to solve this model.

\subsection{Optimization Particle Swarm}

Optimization Particle Swarm was devised by Eberhart and Kennedy in 1995 [38, 39].

\subsubsection{How the binary optimization particle swarm works:}

This algorithm randomly generates a swarm of particles, where each particle represents an acceptable solution of the possible solutions to the problem. Therefore, determining which the best particle is requires the algorithm to search in an iterative manner using two equations. The first is called the particle velocity equation (speed equation) [40].

$$
\begin{aligned}
& V_{i j}^{t+1}=\mathrm{W} V_{i j}^{t}+c_{1} r_{1 j}\left(\text { pbest }_{i}^{t}-X_{i j}^{t}\right)+c_{2} r_{2 j}\left(\text { gbest }_{i}^{t}-\right. \\
& \left.X_{i j}^{t}\right)
\end{aligned}
$$

where: i: Denotes the particle number; $j$ : the number of elements inside the particle; $V_{i j}^{t}$ : The velocity of the particle $i$ in the previous instant $\mathrm{t} ; V_{i j}^{t+1}$ : The velocity of the particle $\mathrm{i}$ in the next instant $\mathrm{t}+1$; pbest $_{i}^{t}$ :The most appropriate value reached by the i-particle until the iteration t; gbest $t_{i}^{t}$ : The most appropriate value within the swarm has been reached up to repetition $\mathrm{t}, \quad$ gbest $_{i}^{t}=\max \left(\right.$ pbest $_{1}^{t}$, pbest $_{2}^{t}$, ...pbest $\left.t_{55}^{t}\right) . \mathrm{r}_{1 \mathrm{j}}$ and $\mathrm{r}_{2 j}$ : Random values to ensure diversity of investigation and fall within the range $[0,1] ; X_{i j}^{t}$ : The position of the particle $\mathrm{i}$ in the previous instant $\mathrm{t}$; W: A variable representing a percentage of the particle velocity at the previous moment; $c_{1}$ and $c_{2}$ : Acceleration variables that control the speed of reaching the best solution. In applications that use this algorithm, the variables $\left(\mathrm{c}_{1}\right.$ and $\mathrm{c}_{2}$ and $\mathrm{W}$ ) are calibrated experimentally [41, 42]. Value of $\mathrm{W}$ is confined within the range [0.3- 0.9], as for the two variables $\mathrm{c}_{1}$ and $\mathrm{c}_{2}$, they have a field [0.4-2]. Consequently, a set of experiments were conducted to reach the appropriate values. Equation (7) determines the probability of a change in the values of the particle's forming elements. The second equation is the equation for the new state of the particle, as expressed by equation 8 [43]. 


$$
X_{i j}(\mathrm{t}+1)=\left\{\begin{array}{lll}
1 & \text { if } & u_{i j}<\operatorname{sig}\left[v_{i j}(t+1)\right] \\
0 & \text { if } & u_{i j} \geq \operatorname{sig}\left[v_{i j}(t+1)\right]
\end{array}\right.
$$

$u_{i j}$ : A random value within the interval $[0,1]$ generated according to an equal probability function at the beginning of each iteration.

$\operatorname{sig}\left(v_{i j}(\mathrm{t})\right)=\frac{1}{1+e^{-v_{i j}(t)}}$

Sigma function $\operatorname{sig}(\mathrm{v})$ aims to narrow the numeric values into confined space $[0,1]$ in order to improve the performance of the algorithm [44]. Figure 2 shows a systematic diagram for working the binary optimization particle swarm.

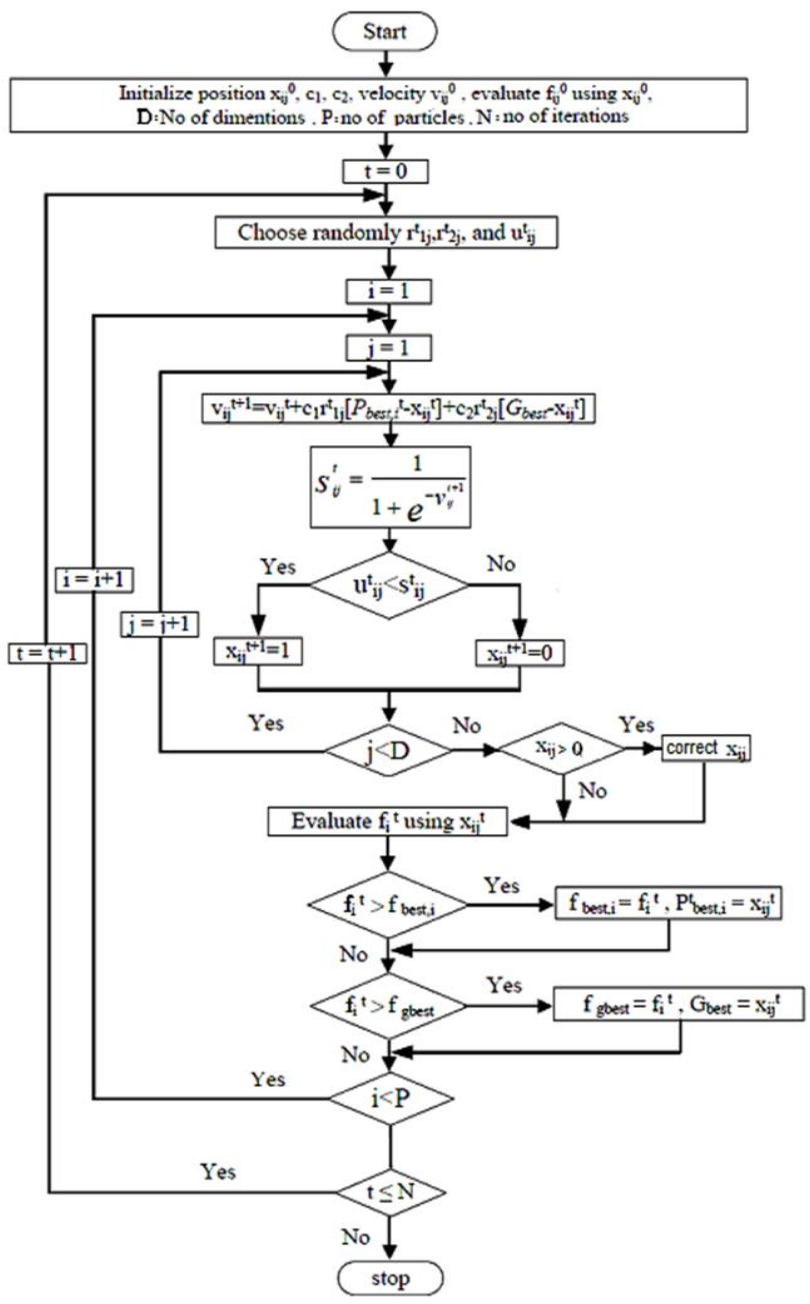

Figure 2: Illustrates flow chart of methodology [45]

\section{Results and discussion}

Initially, a random generation of particles (acceptable solutions) is generated, and then the velocity equation is provided with the necessary random variables $\left(\mathrm{r}_{1 \mathrm{j}}{ }_{1} \mathrm{r}_{2 \mathrm{j}}\right)$, the variables $\left(\mathrm{C}_{1}\right.$, $\mathrm{C}_{2}, \mathrm{~W}$ ), and the initial velocity calculated Figure 3 shows the calibration curve for the $\mathrm{C}_{1}$ and $\mathrm{C}_{2}$ variables, which were obtained experimentally, as it appears that the best value obtained is 1.9.
As for the variable $\mathrm{W}$, after performing the experimental calibration, the best value is 0.4 .

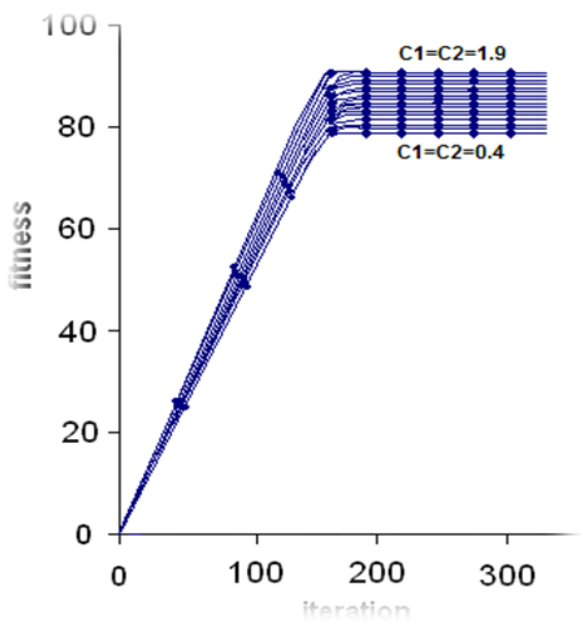

Figure 3: Calibration of $\mathrm{C}_{1}, \mathrm{C}_{2}$ value

After that, it is entered into an iterative loop to improve the solutions generated, where in each iteration the following is done: 1- Generating a vector (uij) from random values confined to the interval $[0,1]$ according to an equal probability function, where (uij) will be used later in the process of changing the state of the solution.

2- Calculate the velocity (v) for each element of the problem elements of the particle, then calculate the value of Sig (v).

3- Conducting a comparison process between the values of (uij) and Sig (v), where the comparison process results in a change in the position of the problem elements of the particle.

4- Calculation of the best fitting value (pbest) for the particle and the best fitting value (gbest) at the swarm level (this is equivalent to knowing the best solution in this iteration) [46].

Then the second iteration is taken, where the same previous steps are repeated until the best solution is accomplished. As a result, the weight of each substance in unite volume of the best mixture shown in the Table 2 .

Table 2: shows the weight of each substance in unite volume

\begin{tabular}{|c|c|c|c|c|}
\hline Component & Cement & Filler & Acrylic & Water \\
\hline $\begin{array}{c}\text { Weigh (in } \\
\text { designed } \mathrm{cm}^{3} \text { ): gr }\end{array}$ & 0.4239 & 1.0580 & 0.1056 & 0.3388 \\
\hline
\end{tabular}

By substituting the values shown in the previous table, which represent the components of the cement-based waterproof concrete mixes, it is noticed that it achieves the mathematical model, which represents the lowest value of the target function of (0.1918) SP for each $\mathrm{cm}^{3}$.

\section{Conclusion}

Most of the investigation results of engineering studies depend on the principle of trial and error in decision-making, which requires a lot of time and effort and does not guarantee reaching the optimum solution. Whereas, mathematical models provide mathematically proven optimum solutions to problems that can be formulated according to a mathematical model. The 
proposed model was solved by using the binary optimization particle swarm, the laboratory experimental results of the permeability showed the efficiency of the model in determining the exact proportions of the materials included in composition of cement-base waterproofing concrete mixes according to the imposed engineering conditions at the low-cost.

\section{Aknowledgment}

This research is carried out within the framework of the "National Project of Buildings and Infrastructures Demolition Recycling and Reusing "winner of financing the Fund for Scientific Research and Technological Development in Higher Education in Syria, by Ministerial Decision / Contract / No. / 7/20/2016.

The authors are grateful to the Middle East University, Amman, Jordan for the financial support granted to cover the publication fee of this research article.

\section{Ethical issue}

Authors are aware of, and comply with, best practice in publication ethics specifically with regard to authorship (avoidance of guest authorship), dual submission, and manipulation of figures, competing interests and compliance with policies on research ethics. Authors adhere to publication requirements that submitted work is original and has not been published elsewhere in any language.

\section{Competing interests}

The authors declare that there is no conflict of interest that would prejudice the impartiality of this scientific work.

\section{Authors' contribution}

All authors of this study have a complete contribution for data collection, data analyses and manuscript writing.

\section{References}

1 Othman, N, L., et.al. "A Case Study on Moisture Problems and Building Defects” Procedia - Social and Behavioral Sciences 170, 2015.

2 Johan Ahlström., "Corrosion Of Steel In Concrete At VariousMoisture And Chloride Levels" ENERGIFORSK, ISBN 978 91-7673-[133-8], (2015).

3 Waterproofing and Moisture Proofing of Buildings Code, "Arab Unified Codes for Design And Implementation of Buildings", Council of Arab Ministers of Housing and Construction, (2010).

4 Jomaa H., M.,"Waterproofing and Protecting Reinforced Concrete Structures". (In Arabic) (2007).

5 Almuselhi M. H., "Construction Engineering: Finishing of Building", (2005).

6 Rebuild.,"Advances In Waterproofing Materials \& Technology" A Quarterly Newsletter, Dr. Fixit Institute of Structural Protection and Rehabilitation. Vol.5 No.1 Jan-Mar (2011).

7 Raven, Geo-membrane Installation Guidelines \& Specifications for Rufco 20,30 40 mil Unreinforced and Dura-SKRIM J30 and J45 mil Reinforced (2008).

8 Kim,Sangyong.,et.al." Sustainability Life Cycle Cost Analysis of Roof WaterproofingMethods Considering LCCO2". Sustainability 6 , 158-174 (2014)

9 W Tahri., et.al. "Cost Efficiency and Resistance to Chemical Attack of a Fly ash Geo-polymeric Mortar Versus Epoxy Resin and Acrylic Paint Coatings". European Journal of Environmental Civil Engineering Vol. 21. Issue 5 (2017).

10 Kubal, Michael T. "Construction Waterproofing Handbook", Second Edition, McGraw-Hill Professional (2008).
11 Richard T. Bynum Jr.,"Insulation Handbook", 1 st edition, McGrawHill Professional (2000)

12 W. Yao, Q. Q. Hu, Y. Mu, J. B. Chen, F. Q. Zhao, "Polymer Modified Cementitious Waterproofing Coatings: Application and Problems", Advanced Materials Research, Vol. 936, pp. 1378-1381, (2014).

13 [Tsai-Lung Weng., et.al. "Evaluation of Cementitious Repair Mortars Modified with Polymers" Volume: 9 issue: 1, (2017).

14 CatarinaNeno; Jorge de Brito; RosárioVeiga., "Using Fine Recycled Concrete Aggregate for Mortar Production" Mat. Res. vol.17 no.1 São Carlos Jan./Feb. 2014 Epub Oct 08, (2013).

15 Feras Al adday, Aymen Awad, Altayeb qasem, and Mou'ath Adnan Al-Shaweesh. Improvement of the Physical and Mechanical Properties of Natural Asphalt Mixes Using Petroleum Bitumen and Polyethylene. International Journal of Advanced Trends in Computer Science and Engineering, volume 9, issue 5, September-October 2020, 8894 - 8900. doi.org/10.30534/ijatcse/2020/286952020.

16 Vivian W.Y. Tam., et.al." New Approach in Measuring Water Absorption of Recycled Aggregates", Construction and Building Materials. Volume 22, Issue 3, March (2008)

17 Alsaleh,F., et.al." National Project of Buildings and Infrastructures Rubbles and Demolition Recycling and Reusing", 2nd Report to Ministry of Higher Education, Syrian Arab Republic, March (2017).

18 Fatima Alsaleh, Feras Al Adday, 2020. Properties of Hot Mix Asphalt Containing Reclaimed Asphalt Pavement of the Aleppo highways. International Journal of Emerging Trends in Engineering Research, 2020, 8(8), pp. 4037-4043. doi.org/10.30534/ijeter/2020/02882020.

19 Sonawane, T. R., Pimplikar, S.S.," Use of Recycled Aggregate Concrete". IOSR Journal of Mechanical and Civil Engineering (IOSR-JMCE)(2011)

20 Aymen awad, Feras al adday, Altayeb qasem, Alial-dulaimy. An Experimental Study on the Possibility of Demolition of Destroyed Concrete Buildings with Different Types of Acid. International Journal of Engineering Research and Technology, Volume 13, Number 9 (2020), pp.2297-2304.

21 Feras. Al Adday, 2020. Selecting the Best Method for Adding Recycled Aggregate. International Journal of Emerging Trends in Engineering Research vol. 8, no. 6, pp. 2253-2258, 2020 doi.org/10.30534/ijeter/2020/08862020.

22 Fatima Alsaleh and Feras Al adday, 2020. Manufacture of Lightweight Thermal Insulation Concrete Using Recycled Aggregates and Syrian Pozzolan Int. J. Adv. Trends Comput. Sci. Eng., vol. 8, no. 3, pp. 959-962, 2019 doi.org/10.30534/ijatcse/2020/178932020.

23 R.ShanthiVengadeshwari, Dr.H.N.Jagannatha Reddy “ Optimum Concrete mix Design usingHeuristic Techniques " International Journal of Scientific \& Engineering Research, Volume 4, Issue 8, August (2013).

24 R. S. Kale, S. Y. Kute"Five Layers Artificial Neural Network System [Ann] to Design a Concrete Mix Based on I.S.I. Method". CACE Volume 2, Issue 4 Oct. (2014).

25 Sakshi Gupta, "Concrete Mix DesignUsing Artificial Neural Network" Journal on Today's Ideas -Tomorrow's TechnologiesVol 1, No. 1June (2013).

26 Sakshi Gupta "Using Artificial Neural Network to Predict the Compressive Strength of Concrete containing Nano-silica"Civil Engineering and Architecture 1(3): 96-102, (2013).

27 Bilgil, A.," Estimation of slump value and Bingham parameters of fresh concrete mixture composition with artificial neural network modeling" Scientific Research and Essays Vol. 5(8), pp. 1753-1765, 18 April, (2012).

28 Vagelis G. Papadakis., "Effect of supplementary cementing materials on concrete resistanceagainst carbonation and chloride ingress "Cement and Concrete Research 30 (2000)

29 Y. CengizToklu "Aggregate Blending Using Genetic Algorithms" Volume 20, Issue 6 (2005).

30 Xiaojie Zhang, DianmoZheng "Uniform Design for Preparation of CementitiousCapillaryCrystalline Waterproofing Coating" Advanced Materials Research Vols 374-377 (2012).

31 Zhang Y, Du XL, Li Y, Yang FM, Li ZG. Research on Cementitious Capillary Crystalline Waterproofing Coating for Underground 
Concrete Works. AMR 2012;450-451:286-90. https://doi.org/10.4028/www.scientific.net/amr.450-451.286.

StepanBohus, et.al. "Fly-ash usage in new cement-based material for concretewaterproofing" Advanced Materials Research Vols 535-537 (2012).

32 Pushkarova, Kateryna; Sukhanevych, Maryna; Bondar, Kateryna. "The Principles of Composite Construction Penetrability Waterproofing Mortars with Increased Service Life" ПІДВОДНІ ТЕХНОЛОГІї.( 2015). http://repositary.knuba.edu.ua:8080/xmlui/handle/987654321/796.

33 CzarneckiLecha, Sokołowska Joanna Juliab"Optimization of Polymer-Cement Coating Composition using Material Model" Key Engineering Materials Vol 466 (2011).

34 Feras Al Adday, 2020. Investigational Assessment of Modified Performance of Used Tire Concrete Mixtures. International Journal of Emerging Trends in Engineering Research, volume 8. issue 5, May 2020, 1804- 1808. doi.org/10.30534/ijeter/2020/52852020.

35 Alhusari S., "Construction Materials and their Tests", Aleppo University Publications, (2008).

36 Feras Al adday, 2020. Re-Evaluating Elements of an Existing MultiLevel Intersection Intersection: Na ur Interchange as a Case Study. International Journal of Engineering Research and Technology. ISSN 0974-3154, Volume 13, Number 8 (2020), pp. 1847-1853.

37 Feras Al adday, Aymen Awad, 2020. A Review of the Status of Scientific Research and Practical Techniques Related to Using Cement Kiln Dust to Stabilize Weak Soils. International Journal of Advanced Trends in Computer Science and Engineering. Volume 9, No.4, July $\quad-\quad$ August 2020 . https://doi.org/10.30534/ijatcse/2020/65942020.

38 Kennedy jf. eberhart rc., "Particle Swarm Optimization", IEEE international conference on neural networks, vol. 4 (1948)

39 Eberhart rc. kennedy jf.,"A new optimizer using particle swarm theory". international symposium on micromachine and human science, Nagoya, (1995)

40 Ying t. yuhui s. guoyin w., "Advances in Swarm Intelligence Part II"., Springer, (2011).

41 Ajith a.; crosan c.; ramos v., "Swarm Intelligence in Data Mining" , Springer, (2006).

42 Singla s.; dharminder k.,"a hybrid pso approach to Automate Test Data Generation for Data Flow Coverage with Dominance Concepts". International Journal of Advanced Science and Technology, (2011) .

43 Parsopoulos ke.; vrahatis mn.,"particle Swarm Optimization and Intelligence", Springer, (2010).

44 Manoj tk.; felix t.,"swarm intelligence". in-tech, (2007)

45 Satyobroto t.,"mathematical Modelling and Application of Particle Swarm Optimization", Blekinge Institute of Technology, (2011).

46 Parpinelli r.; lopes hs., "theory and New Applications of Swarm Intelligence", Springer, (2012). 